\title{
Avaliação dos Impactos das Mudanças na Cobertura da Terra e Cenário de Emissões (RCP 8.5) no Balanço de Água na Bacia do Rio Madeira
}

\author{
Weslley de Brito Gomes ${ }^{1}$ (D), Francis Wagner Silva Correia ${ }^{2}$, Vinicius Capistrano ${ }^{2}$, \\ José Augusto Paixão Veiga ${ }^{2}$, Leonardo Alves Vergasta ${ }^{1}, \operatorname{Sin}$ Chan $\mathrm{Chou}^{3}$, André de Arruda Lyra ${ }^{3}$, \\ Vinicius Machado Rocha ${ }^{4}$ \\ ${ }^{1}$ Instituto Nacional de Pesquisas da Amazônia, Escritório Central do LBA, Manaus, AM, Brasil. \\ ${ }^{2}$ Universidade do Estado do Amazonas, Manaus, AM, Brasil. \\ ${ }^{3}$ Instituto Nacional de Pesquisas Espaciais, Centro de Previsão de Tempo e Estudos Climáticos, \\ Cachoeira Paulista, SP, Brasil. \\ ${ }^{4}$ Universidade Federal do Recôncavo da Bahia, Cruz Das Almas, Bahia, Brasil.
}

Recebido em: 28 de Outubro de 2019 - Aceito em: 26 de Agosto de 2020

\begin{abstract}
Resumo
Nesse estudo avaliou-se os impactos do aumento dos GEE's (cenário RCP 8.5) e dos desflorestamentos no ciclo da água na bacia do rio Madeira, utilizando o Modelo Regional Eta e o Modelo Hidrológico de Grandes Bacias (MGB), forçado com o Brazilian Earth System Model Ocean-Atmosphere versão 2.5 (BESM-OA 2.5). No cenário RCP 8.5, o modelo apresentou sensibilidade sobre toda a bacia do Madeira, com aumento da ordem de $4.0{ }^{\circ} \mathrm{C}$ na temperatura. $\mathrm{O}$ aumento foi intensificado com os cenários de desflorestamentos de $2050\left(4.8^{\circ} \mathrm{C}\right)$ e $2100\left(6.2{ }^{\circ} \mathrm{C}\right)$. Nos cenários de desflorestamento predominou-se o Mecanismo de Retroalimentação Negativo, pois embora haja reduções na precipitação e evapotranspiração, a convergência de umidade aumentou em todos os cenários. Observou-se aumento das descargas na maioria das estações para todos os cenários futuros RCP 8.5 e desflorestamento. $\mathrm{O}$ aumento da precipitação na estação seca explicou em parte o aumento das vazões e na área de inundação sobre a bacia do Madeira. O aumento na precipitação à montante da bacia e a mudança nos parâmetros do solo, associada às alterações no uso da terra, contribuíram para o aumento da vazão e área de inundação sobre a bacia do Madeira. As alterações nas descargas e na área de inundação podem ter efeitos negativos, com prejuízos e danos ao meio ambiente, nos recursos hídricos, nos principais setores da economia, afetando de forma direta as comunidades que vivem às margens dos rios, principalmente as populações vulneráveis da bacia do Madeira.
\end{abstract}

Palavras-chave: Rio Madeira, modelo hidrológico, vazão, área de inundação.

\section{Assessments of the Impacts of Land Use and Cover Change and Emission Scenarios (RCP 8.5) on the Water Budget in the Madeira River Basin}

\begin{abstract}
In this study, we evaluated the impacts of increased GHGs (RCP 8.5 scenario) and future deforestations on the water cycle in the Madeira River basin by using the Eta Regional Model and MGB-IPH Large-scale Hydrological Model, forced by Brazilian Model of the Terrestrial System (BESM-AO 2.5). In the RCP 8.5 scenario, the model demonstrated sensitivity over the entire Madeira basin, with a temperature increase of $4.0^{\circ} \mathrm{C}$. The increase was intensified with the deforestation scenarios for $2050\left(4.8^{\circ} \mathrm{C}\right)$ and $2100\left(6.2^{\circ} \mathrm{C}\right)$. In the deforestation scenarios, the Negative Feedback Mechanism (NFM) was predominant because, although there were reductions in precipitation and evapotranspiration, the convergence of humidity presented an increase in all the scenarios. Regarding the hydrological processes, an increase in the discharges in most stations for all future scenarios for RCP8.5 and deforestation was observed. The increase in precipitation in the dry season explains in part the increase in the discharges and in the flood area in the Madeira basin. The increased upstream precipitation and the changes in soil parameters associated with the changes in land use contributed to the increase in the flood area over the Madeira basin. These changes can have negative effects on the environment, on water resources and on the main sectors of the economy, which directly affect the communities that inhabit the river banks, especially the vulnerable populations of the Madeira basin.
\end{abstract}

Keywords: Madeira River, hydrological model, flow, flood area.

Autor de correspondência: Weslley de Brito Gomes, weslley.brito.gomes@gmail.com. 


\section{Introdução}

A mais extensa bacia hidrográfica do planeta está localizada na região Amazônica. Com uma área de mais de 6 milhões de $\mathrm{km}^{2}$, está presente em vários países da América do Sul estendendo-se desde os sopés andinos até o Oceano Atlântico (Eva e Huber, 2005; Filizola et al., 2002). O rio Amazonas apresenta uma área de drenagem com cerca de um terço do continente Sul-americano e uma vazão média de $209.000 \mathrm{~m}^{3} \mathrm{~s}^{-1}$, contribuindo com aproximadamente $15 \%$ do volume de água doce afluente aos oceanos (Molinier et al., 1996).

Um dos principais afluentes da margem direita do Amazonas é o rio Madeira. A bacia do rio Madeira abrange cerca de $23 \%$ da bacia Amazônica e desempenha papel fundamental no desenvolvimento social e econômico da região através da navegação, irrigação de cultivos agrícolas e a geração de energia elétrica por meio das usinas de Jirau e Santo Antônio (Siqueira et al., 2015). No entanto, a bacia Amazônica, e principalmente a bacia do Madeira, são sensíveis às variabilidades e mudanças no sistema climático terrestre, devido tanto às variações naturais quanto às antropogênicas: aumento dos gases do efeito estufa (GEE's) pela queima de combustíveis fósseis e os desflorestamentos (Espinoza et al., 2014; Zhang et al., 2015; Marengo e Espinoza, 2016; Sorribas et al., 2016; Alves et al., 2017). A taxa média anual do desflorestamento na Amazônia é da ordem de $14.300 \mathrm{~km}^{2}$ com um total acumulado de $428.720 \mathrm{~km}^{2}$ no período de 1988 2017 , correspondendo a aproximadamente a $16 \%$ da floresta Amazônica brasileira (INPE, 2017).

A bacia do rio Madeira tem experimentado intenso desflorestamento com a conversão de floresta em área agrícolas e ou pastagem para criação de gado (Trancoso et al., 2009). Somente nos estados localizados na área hidrográfica da bacia do rio Madeira o desflorestamento acumulado foi de aproximadamente $147.000 \mathrm{~km}^{2}$, representando $33 \%$ do total de desflorestamento na Amazônia Legal (INPE, 2017). Essas mudanças no uso e cobertura da terra tem alimentado o interesse científico sobre os potenciais impactos que essas mudanças possam gerar no ciclo hidrológico da bacia Amazônica. Diferentes estudos têm mostrado que os desflorestamentos na região tropical podem conduzir a impacto significativo do clima, com aumento de temperatura da superfície e mudanças regionalizadas no regime hidrológico (Sampaio et al., 2007; Alves et al., 2017; Silveira et al., 2017). Além disso, nos últimos anos a variabilidade no clima tem afetado os principais rios da bacia Amazônica. $\mathrm{O}$ aumento na frequência e intensidade dos eventos de secas e enchentes produziram prejuízos e danos no meio-ambiente, nos recursos hídricos, na economia e nas cidades e comunidades que vivem às margens dos rios, principalmente as populações vulneráveis da Amazônia (Espinoza et al., 2014; Doughty et al., 2015; Marengo e Espinoza, 2016). Eventos de enchentes e precipitações extremas tem afetado a bacia do rio Madeira recentemente (verão 2013-14), trazendo transtornos e prejuízos para população, tais como: famílias desabrigadas, interdição de estradas, isolamentos de comunidades, prejuízos na agricultura e transporte (Marengo e Espinoza, 2016).

Os cenários de mudanças no clima previsto pelos modelos climáticos do sistema terrestre, utilizando cenários de emissões do Quinto Relatório de Avaliação do Painel Intergovernamental sobre Mudanças no Clima (AR5IPCC), indicam reduções no regime de precipitação e aumento na frequência de eventos extremos na maior parte da Amazônia ocidental (Marengo et al., 2011; Marengo et al., 2012; Chou et al., 2014; Siqueira et al., 2015; Sorribas et al., 2016). Avaliando as projeções futuras de mudanças no clima do AR5-IPCC, Sorribas et al. (2016) observaram condições mais úmidas (secas) sobre o oeste (leste) da bacia Amazônica no fim do século XXI. Siqueira et al. (2015) também avaliando as projeções do clima futuro e as mudanças na cobertura vegetal na Amazônia, observaram que os efeitos das mudanças no clima sobre o regime hidrológico (vazão) resultaram em reduções em descargas mais baixas e mais altas com diferentes extensões espaciais com a conversão de floresta para pastagem. Em geral, o aumento nas taxas de desmatamento minimizou parcialmente os efeitos da redução da precipitação. Entretanto, ambos os trabalhos mostraram incertezas devido à variabilidade dos resultados entre os modelos globais utilizados. Diante das alterações no uso e cobertura da terra na Amazônia e os efeitos das mudanças climáticas globais, uma questão importante levantada na comunidade científica é: "De que maneira o aumento dos GEE's e as mudanças no uso da terra podem modificar o balanço de água na bacia do rio Madeira?". Visando responder esta pergunta, esse estudo tem por objetivo avaliar os impactos do aumento dos GEE's e dos desflorestamentos nos ramos atmosférico e terrestre do ciclo da água na bacia do rio Madeira, utilizando o Modelo Regional Eta e o Modelo Hidrológico de Grandes Bacias (MGB), cenário de emissões do AR5-IPCC RCP 8.5 e também cenários de desflorestamentos na Amazônia referentes ao estado atual e projeções para situações futuras.

\section{Materiais e Métodos}

Para avaliação dos efeitos antropogênicos (aumento dos GEE's e desflorestamento) no ramo atmosférico do balanço de água na bacia do rio Madeira realizaram-se simulações numéricas para o clima presente (1960 - 2005) e projeções climáticas futuras (2071 a 2100) com diferentes cenários de desflorestamento na Amazônia. Para isso utilizou-se o Modelo Regional Eta (área limitada), forçado com as condições iniciais e de contorno provenientes do modelo de circulação geral Brazilian Earth System Model Ocean-Atmosphere versão 2.5 (BESM-OA 2.5) por meio do processo de downscaling dinâmico. 
Daqui por diante a simulação de downscaling será referida por Eta-BESM-OA. Para avaliação dos impactos no ramo terrestre do balanço de água (vazão e área de inundação) o Modelo Hidrológico de Grandes Bacias do Instituto de Pesquisas Hidráulicas (MGB-IPH) foi forçado com as condições climáticas do Modelo Regional Eta.

\section{1. Área de estudo}

A bacia do rio Madeira possui uma área de drenagem de aproximadamente 1.4 milhão de $\mathrm{km}^{2}$, da qual 51\% pertencem à Bolívia, $42 \%$ ao Brasil e $7 \%$ ao Peru (Ribeiro Neto, 2006) (Fig. 1). Apresenta uma vazão média de aproximadamente de $31.704 \mathrm{~m}^{3} \mathrm{~s}^{-1}$, que corresponde a $15 \%$ da descarga média do Rio Amazonas na sua foz (Siqueira et al., 2015). A precipitação média na bacia é da ordem de $1.834 \mathrm{~mm}$ ano ${ }^{-1}$ (Molinier et al., 1996), com uma intensa variabilidade espacial variando de $255 \mathrm{~mm}$ ano $^{-1}$ na estação de Caracato $(2650 \mathrm{~m})$ a mais de $3000 \mathrm{~mm}$ $\mathrm{ano}^{-1}$ em estações Andinas localizadas em torno de $1500 \mathrm{~m}$ de altitude (Espinoza Villar, 2009).

\subsection{Dados}

Utilizou-se para avaliação do desempenho do modelo regional Eta-BESM-OA na representação da precipitação na bacia do rio Madeira as reanálises do Era-Interim (European Centre for Medium-Range Weather Forecasts ECMWF), com resolução espacial de $1.0^{\circ} \times 1.0^{\circ}$ (Dee et al., 2011). A avaliação foi realizada para o período de 1979 a 2005. Para a avaliação do desempenho do modelo MGBIPH utilizaram-se as medições de vazão das estações fluviométricas da Agência Nacional de Águas (ANA), disponíveis no Sistema de Informações Hidrológicas (HidroWeb) para o período de 1995 e 2005 . As estações utilizadas nesse estudo são apresentadas na Fig. 1 e Tabela 1.

\subsection{Cenários de emissão e desflorestamento}

Neste estudo foram utilizados três cenários de desflorestamento para a bacia do rio Madeira: a) mapa atual de vegetação referente ao ano base de 2015 ; b) cenário projetado para 2050 e c) cenário projetado para 2100 (Fig. 2). O mapa de uso e cobertura da terra elaborado pelo Projeto ProVeg (Sestini et al., 2002) e dados do Projeto de Estimativa do Desflorestamento Bruto da Amazônia -

Tabela 1 - Estações fluviométricas da Agência Nacional de Águas (ANA) e áreas de drenagem correspondentes.

\begin{tabular}{cccccc}
\hline $\mathrm{N}^{\circ}$ & Código & Nome & $\mathrm{A}\left(\mathrm{km}^{2}\right)$ & Lat & Lon \\
\hline 1 & 15250000 & Guajará-Mirim & 589497 & $-10.79^{\circ} \mathrm{S}$ & $-65.35^{\circ} \mathrm{W}$ \\
2 & 15400000 & Porto Velho & 954285 & $-8.75^{\circ} \mathrm{S}$ & $-63.92^{\circ} \mathrm{W}$ \\
3 & 15430000 & Ariquemes & 7795 & $-9.93^{\circ} \mathrm{S}$ & $-63.06^{\circ} \mathrm{W}$ \\
4 & 15580000 & Tabajara & 60212 & $-8.93^{\circ} \mathrm{S}$ & $-62.05^{\circ} \mathrm{W}$ \\
5 & 15630000 & Humaitá & 1066240 & $-7.50^{\circ} \mathrm{S}$ & $-63.01^{\circ} \mathrm{W}$ \\
6 & 15700000 & Manicoré & 1157516 & $-5.81^{\circ} \mathrm{S}$ & $-61.30^{\circ} \mathrm{W}$ \\
\hline
\end{tabular}

Fonte: Agência Nacional de Águas (ANA).

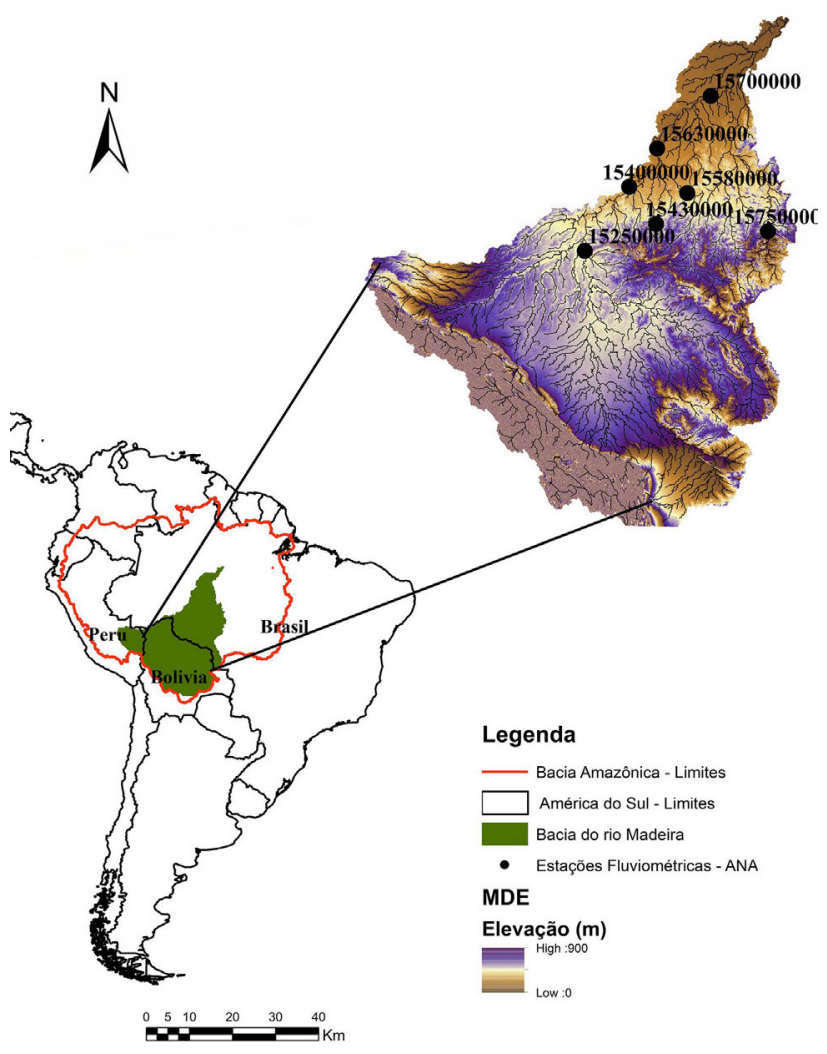

Figura 1 - Localização da bacia hidrográfica do rio Madeira. Destacamse também o modelo digital de elevação (MDE) e as estações fluviométricas selecionadas na avaliação do Modelo Hidrológico de Grandes Bacias (MGB-IPH).

PRODES-DIGITAL (INPE, 2017) com as cenas de desflorestamento para o ano de 2015 foram utilizados no mapa atual de vegetação. Os cenários de desflorestamentos futuros para os anos de 2050 e 2100 foram elaborados a partir do modelo de dinâmica de paisagem denominado DINAMICA da paisagem (Soares-Filho et al., 2004). O bioma pastagem degradada representou o desflorestamento na bacia Amazônica. Também neste estudo considerouse o cenário de emissão baseado no Representative Concentration Pathway 8.5 (RCP 8.5) do IPCC AR5 (2013). Os cenários de emissão (RCP's) representam diferentes trajetórias de concentração dos gases de efeito estufa no clima futuro (Van Vuuren et al., 2011a, 2011b). Nesses cenários as possíveis alterações no sistema terra-atmosfera são concebidas pelos valores das forçantes radiativas nas quais compreendem valores entre 2.6 e $8.5 \mathrm{~W} \mathrm{~m}^{2}$. O RCP 8.5 (2.6) é o mais pessimista (otimista) e resulta em um aquecimento médio global de $2.6{ }^{\circ} \mathrm{C}$ a $4.8{ }^{\circ} \mathrm{C}\left(0.3{ }^{\circ} \mathrm{C}\right.$ a $1.7^{\circ} \mathrm{C}$ ) ao final do século XXI.

\subsection{Descrição dos modelos e estratégia de integração numérica}

O modelo regional Eta do Centro de Previsão do Tempo e Estudo Climáticos do Instituto Nacional de Pes- 

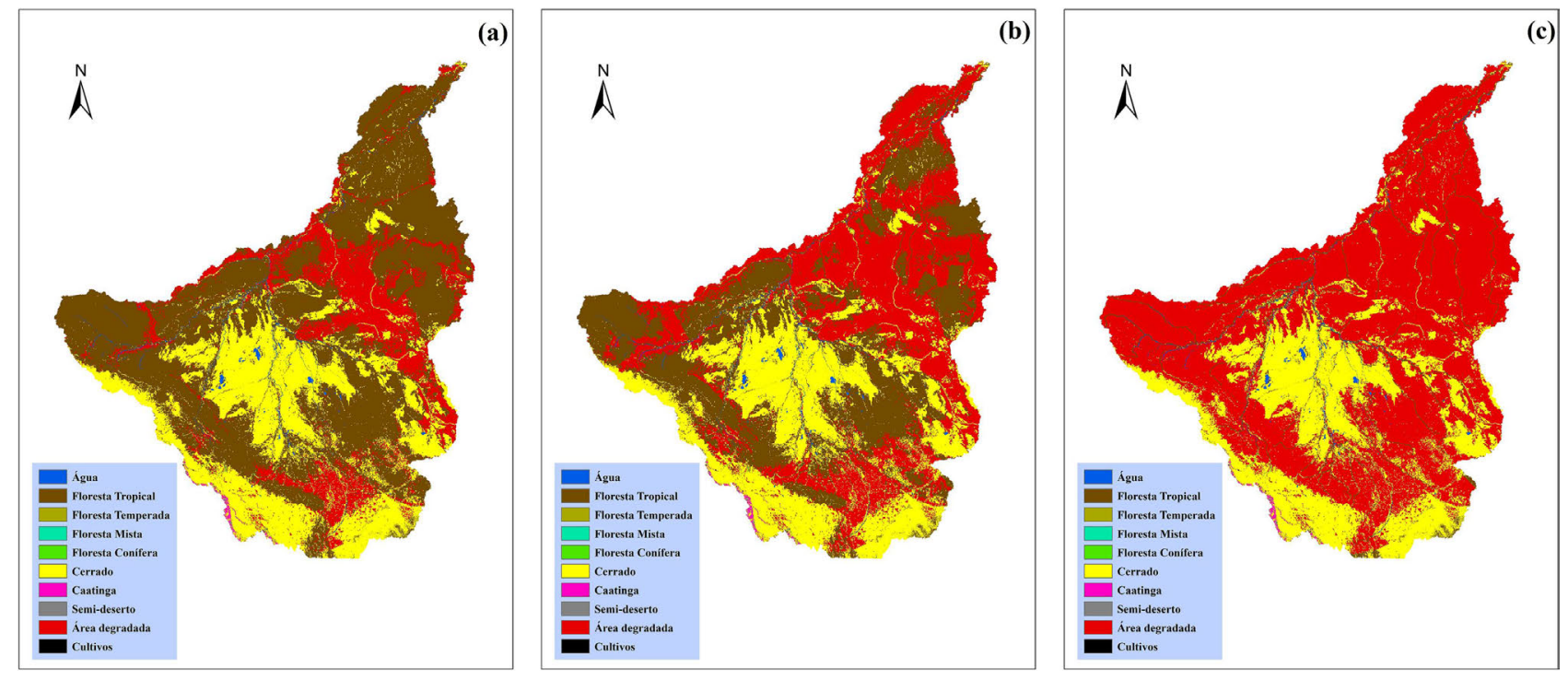

Figura 2 - Cenários de cobertura vegetal para bacia do rio Madeira utilizados nas simulações com o modelo regional Eta-BESM-AO e no modelo hidrológico MGB-IPH. (a) Mapa de vegetação elaborado pelo Projeto ProVeg com áreas desflorestadas (ano base 2015); (b) Cenários projetados para os anos de 2050 e (c) 2100 provenientes do Modelo DINAMICA.

quisas Espaciais (CPTEC/INPE) foi utilizado na geração do clima presente e projeções futuras (Chou et al., 2014a; Chou et al., 2014b). A dinâmica do modelo regional é desenvolvida na coordenada vertical eta (Mesinger, 1984), útil para operar em regiões de orografia íngremes, como a Cordilheira dos Andes, na América do Sul. A precipitação é calculada pelo esquema de parametrização de cumulus de Betts-Miller-Janjic (Janjic 1994) e pelo esquema de microfísica da nuvem de Zhao (Zhao et al., 1997). Os esquemas de radiação são do GFDL para ondas curtas Lacis e Hansen (1974) e longas Fels e Schwarzkopf (1975). Os processos de superfície são representados pelo NOAH (Ek et al., 2003), que contém 4 camadas de solo para a temperatura e umidade, assim como 12 tipos de vegetação e 7 tipos de textura de solo. O mapa da vegetação revisado inclui o arco do desmatamento na Amazônia (Sestini et al., 2002). Neste estudo o modelo foi configurado com resolução de $20 \mathrm{~km}$ na horizontal e 38 níveis na vertical.

O Brazilian Earth System Model Ocean-Atmosphere versão 2.5 - BESM-OA 2.5 (Nobre et al., 2013) é um modelo espectral Euleriano com truncamento T62 e 28 níveis na atmosfera. Este modelo é constituído pelo modelo de circulação geral da atmosfera (AGCM) do Centro de Previsão de Tempo e Estudos Climáticos - CPTEC/ INPE (Figueroa et al., 2016) acoplado ao modelo de circulação geral oceânico (OGCM) - Modelo Oceânico Modular versão 4p1 (MOM4p1) do Geophysical Fluid Dynamics Laboratory Climate via GFDLös Flexible Modular System (Griffies, 2009). As parametrizações físicas incluem o modelo de superfície Simplified Simple Biosphere Model - SSiB (Xue et al., 1991), o esquema de turbulência na camada limite planetária de Mellor-Yamada
2.0 (Mellor e Yamada, 1982), o esquema de convecção profunda de Grell e Devenyi (2002) e a parametrização de convecção rasa de Tiedtke (1984).

O Modelo Hidrológico de Grandes Bacias - MGBIPH (Collischon, 2001; Collischon et al., 2007) é um modelo distribuído desenvolvido para aplicações em grandes bacias hidrográficas com limitação de dados $\left(10.000 \mathrm{~km}^{2}\right)$. O MGB-IPH é um modelo baseado em processos que simula o ciclo hidrológico através de relações físicas e conceituais. São simuladas todas as etapas do ciclo hidrológico terrestre, incluindo balanço de água no solo, evapotranspiração, interceptação, escoamento superficial, subsuperficial e subterrâneo e escoamento na rede de drenagem. A versão do MGB-IPH aplicado neste estudo utiliza o modelo de propagação inercial ou hidrodinâmico proposto por Paiva et al. (2013). O modelo inercial é fundamentado nas equações da continuidade e dinâmica de Saint Venant no qual permite simular rede de canais com confluências e difluências, vazão, nível d'água (cota) e extensão das áreas inundadas ao longo da bacia (Paiva et al., 2011, 2013). A maioria dos parâmetros do modelo hidrológico é relacionada às características físicas da bacia, como topografia, cobertura vegetal e solo (Fig. 2), que são obtidas via imagens de satélites, mapas digitalizados e modelo digital de elevação MDE (Getirana et al., 2010; Pereira, 2010). Os demais parâmetros são calibrados com algoritmo de otimização global multiobjetivo MOCOM-UA (Yapo et al., 1998).

Neste estudo foram realizados quatro experimentos numéricos. No primeiro experimento incluiu-se o mapa atual de vegetação com desflorestamento para o ano de 2015 e o clima presente proveniente do Eta-BESM-OA. Esse experimento consistiu-se de uma integração contínua 
de 46 anos inicializada às $00 \mathrm{~h}$ (TMG - Tempo Médio de Greenwith) de 01 de Janeiro de 1960. A concentração de dióxido de carbono $\left(\mathrm{CO}_{2}\right)$ permaneceu constante em 330 ppm durante a integração. Nos experimentos de clima futuro utilizaram-se as projeções de emissões RCP 8.5 produzidas Eta-BESM-OA 2.5 e o mapa de vegetação de 2015 e cenários de desflorestamento para os anos 2050 e 2100. No clima futuro, as integrações foram realizadas de forma contínua para o período de 2071 a 2100 (31 anos), considerando um tempo de equilíbrio de um ano. Os limites laterais são atualizados com as variáveis de estado do modelo BESM-OA 2.5 a cada intervalo de 6 horas. O modelo atualizou a concentração equivalente de $\mathrm{CO}_{2}$ a cada 3 anos. A temperatura da superfície do mar (TSM), a umidade inicial do solo e a temperatura do solo foram obtidas do BESM-OA 2.5 com TSM atualizado diariamente no modelo regional Eta.

\subsection{Remoção do viés}

As simulações de precipitação provenientes do modelo Eta-BESM-OA foram utilizadas para forçar o modelo MGB-IPH no clima presente e nas projeções futuras. Entretanto, devido aos erros sistemáticos presentes nos modelos climáticos realizou-se o processo de correção do viés conforme proposto por Silva e Collischonn (2006). Os métodos de correção dos erros sistemáticos mais empregados são baseados numa transformação da curva de distribuição de probabilidades de precipitação (Hay et al., 2002 e Wood et al., 2002). No presente estudo, para correção dos erros sistemáticos do modelo regional Eta-BESMOA se utilizou a função de distribuição de probabilidade normal tipo $t$ de Student (Spiegel, 1972), aplicada aos valores médios diários de precipitação observada (EraInterim) e modelada (Eta-BESM-OA). Para avaliação do desempenho das descargas (vazões) simuladas com a precipitação corrigida do modelo Eta-BESM-OA utilizou-se as métricas estatísticas: coeficiente de Nash-Sutcliffe (ENS) (Nash; Sutcliffe, 1970), o coeficiente de Nash-Sutcliffe para valores logarítmicos das vazões (ENSLog) e o erro do volume relativo ( $\Delta \mathrm{V}$ em $\%)$.

\section{Resultados e Discussão}

\subsection{Ramo atmosférico do balanço de água}

As médias para o clima presente e as mudanças na temperatura a 2-m $(\mathrm{T})$, precipitação $(\mathrm{P})$, evapotranspiração (E) e convergência de umidade (C), projetadas para o final do século XXI, nas estações chuvosa (DJF) e seca (JJA), são mostradas nas Figs. 3-4, respectivamente. No clima presente, observa-se pequena variação de temperatura sobre a bacia do Madeira. Isso se deve a intensa disponibilidade de energia solar durante o ciclo anual nessa região. Entretanto, na estação seca (JJA) se observou valor mais baixo de temperatura principalmente na porção sul da bacia. Em ambas as estações se observa mudanças na temperatura $2-\mathrm{m}$ no cenário RCP 8.5 com aumento médio de $4.0^{\circ} \mathrm{C}$ sobre a bacia do Madeira. Esse aumento de temperatura é devido às mudanças na disponibilidade de energia à superfície, aumento no fluxo de calor sensível e a redução na umidade solo (não mostrado). As mudanças na temperatura de 2-m tornam-se mais intensas nos cenários de desflorestamentos na bacia. No cenário de 2050 (2100) o aumento médio na estação úmida foi de $5{ }^{\circ} \mathrm{C}\left(6.5^{\circ} \mathrm{C}\right)$. $\mathrm{Na}$ estação seca o aumento foi $4.7^{\circ} \mathrm{C}\left(5.9^{\circ} \mathrm{C}\right)$ no cenário 2050 (2100). Em termos regionais, esses aumentos foram mais intensos nas porções central e norte da bacia onde as taxas de desflorestamento são maiores em ambos cenários. Nessas regiões, o aumento na temperatura foi decorrente do aumento do fluxo de calor sensível, da redução na evapotranspiração (Fig. 3k,l e Fig. 4k,1) e do comprimento de rugosidade. As reduções na evapotranspiração foram da ordem de $3 \%, 7 \%$ e $14 \%$ em todos os cenários RCP 8.5 e de desflorestamento, apresentando mudanças mais significativas na estação seca e no cenário de 2100 (redução de 22\%). O aumento dos GEEös e os desflorestamentos contribuíram para alterar o clima na bacia do Madeira, e as mudanças no clima tornaram-se mais intensas à medida que se expandiu o desflorestamento na bacia do Madeira.

Para o cenário RCP 8.5 , as mudanças na precipitação apresentaram padrão diferenciado entre as estações seca e úmida. Com exceção dos Andes, na estação úmida observa-se redução na precipitação sobre toda a bacia, principalmente a jusante onde as mudanças são mais intensas (Fig. 3f). Na estação seca, predominou-se o aumento da precipitação na maior parte da bacia, mas no norte a precipitação foi reduzida (Fig. 4f). Na média da bacia, a precipitação reduziu $6.8 \%$ na estação úmida, mas aumentou $5.3 \%$ na seca.

Nos cenários de desflorestamentos futuros se observou uma intensificação nos padrões de redução e aumento na precipitação sobre a bacia do Madeira. Em ambas as estações predominou a redução na precipitação na foz do rio Madeira, nas demais porções da bacia, redução e aumento nas estações chuvosa e seca, respectivamente. $\mathrm{Na}$ média, a precipitação reduziu $7.3 \%$ (11\%) no cenário 2050 (2100) na estação úmida, conforme mostrado na Fig. 5. A redução na precipitação nestes cenários foi fortemente influenciada pelas reduções encontradas na convergência de umidade e na evapotranspiração que agiram no mesmo sentido de reduzir a precipitação nesse período. De forma contrária, na estação seca a precipitação aumentou em 10\% (19\%) no cenário 2050 (2100). Neste caso, o aumento na precipitação deve-se ao aumento na convergência de umidade, uma vez que, a evapotranspiração apresentou reduções de $12 \%$ e $22 \%$ nos cenários 2050 e 2100 , respectivamente (Fig. 5). Recentes estudos têm mostrado uma redistribuição no padrão climatológico da precipitação na bacia Amazônica em cenários de aumento de GEE's (Sorribas et al., 2016; Siqueira et al., 2015), com aumento na 

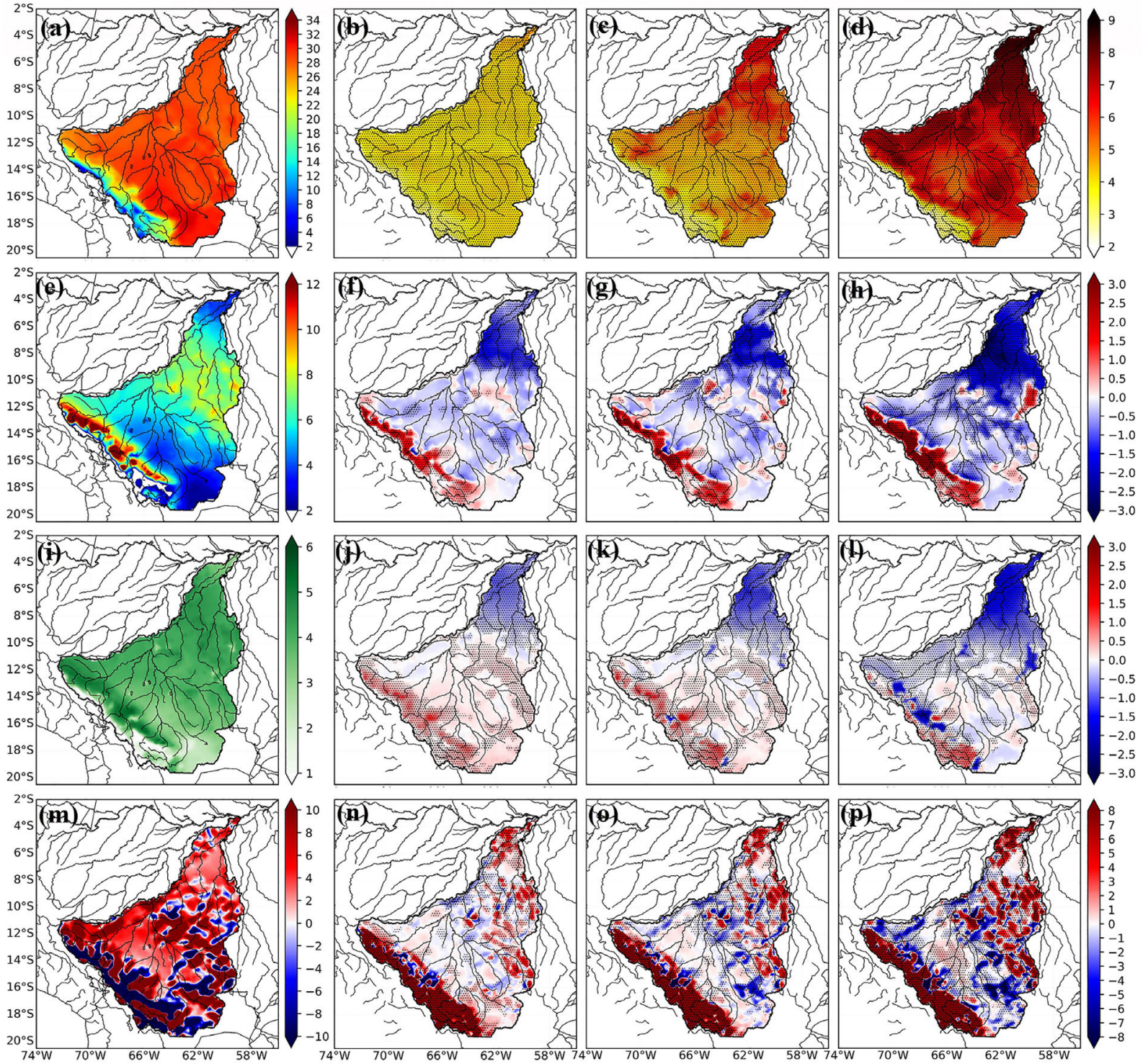

Figura 3 - Impactos decorrentes dos cenários de mudanças no uso e cobertura da terra e cenário de emissão (RCP8.5) para o período úmido (DJF): Linhas de cima para baixo mostram: 1 - Temperatura a $2 \mathrm{~m}\left({ }^{\circ} \mathrm{C}\right) ; 2$ - Precipitação $\left(\mathrm{mm} \mathrm{dia}^{-1}\right) ; 3$ - Evapotranspiração $\left(\mathrm{mm} \mathrm{dia}^{-1}\right) ; 4$ - Convergência de umidade $\left(\mathrm{mm} \mathrm{dia}^{-1}\right):(\mathrm{a}, \mathrm{e}, \mathrm{i}, \mathrm{m})$ Distribuição espacial para o clima presente; $(\mathrm{b}, \mathrm{f}, \mathrm{j}, \mathrm{n})$ Impactos decorrentes do cenário RCP8.5 e desflorestamento para 2015 em relação ao clima presente; (c, g, k, o) Impactos decorrentes do cenário RCP8.5 e desflorestamento para 2050 em relação ao clima presente; (d, h, 1, p) Impactos decorrentes do cenário RCP8.5 e desflorestamento para 2100 em relação ao clima presente. As áreas onde as diferenças são significativas ao nível de confiança de $95 \%$ são marcadas por pontos pretos.

porção oeste-noroeste e redução no leste. Entretanto, no presente estudo se observou aumento da precipitação no sudoeste da bacia do Madeira e redução na sua foz. Esses diferentes efeitos podem estar associados à inclusão das mudanças no uso da terra (desflorestamento) na bacia Amazônica.

$\mathrm{Na}$ avaliação do balanço anual de água sobre a bacia do rio Madeira, observa-se que a precipitação simulada pelo modelo regional Eta-BESM-OA é sempre maior que a evapotranspiração caracterizando a bacia com região de sumidouro de umidade da atmosfera. Para as projeções do cenário de emissão RCP 8.5 e desflorestamento futuros se observa que os impactos no ciclo da água sobre a bacia são intensificados na inclusão dos desflorestamentos. No cenário RCP 8.5, o modelo simulou reduções de $4.3 \%$ na precipitação, $2 \%$ na evapotranspiração e aumento de $24 \%$ na convergência de umidade na média anual. Nesse caso, observa-se que a evapotranspiração e convergência de umidade agiram em sentidos contrários na redução na precipitação, com a evapotranspiração apresentando papel mais preponderante. Com os cenários de desflorestamento para 2050 e 2100 , se observou redução de $4.6 \%$ e $5.9 \%$ na precipitação, $5 \%$ e $16 \%$ na evapotranspiração, respectivamente. Entretanto, na média anual sobre a bacia se obser- 

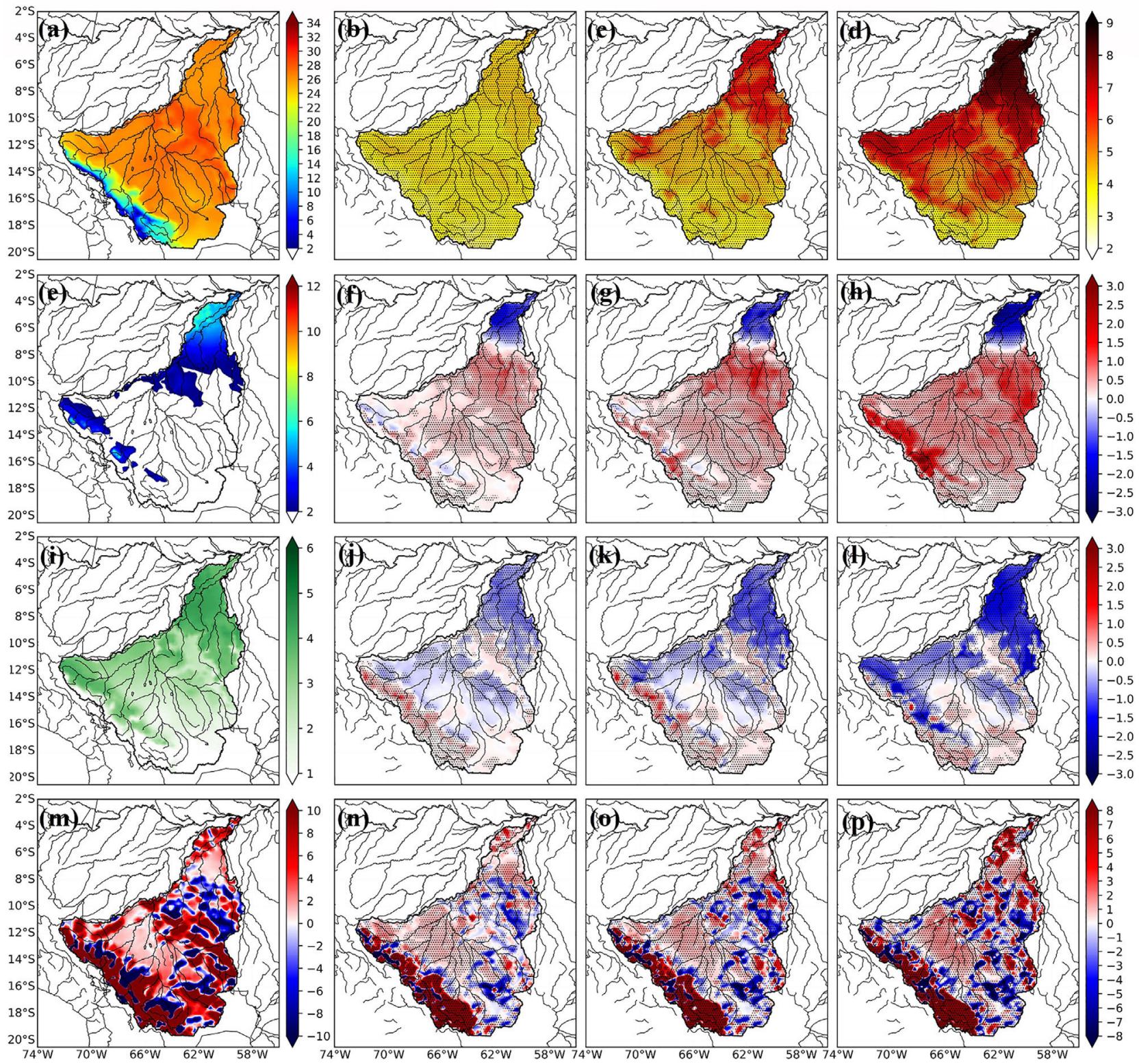

Figura 4 - Impactos decorrentes dos cenários de mudanças no uso/cobertura da terra e cenário de emissão (RCP8.5) para o período seco (JJA): Linhas de cima para baixo mostram: 1 - Temperatura a $2 \mathrm{~m}\left({ }^{\circ} \mathrm{C}\right) ; 2$ - Precipitação $\left(\mathrm{mm} \mathrm{dia}^{-1}\right) ; 3$ - Evapotranspiração $\left(\mathrm{mm} \mathrm{dia}^{-1}\right) ; 4$ - Convergência de umidade $(\mathrm{mm}$ $\left.\operatorname{dia}^{-1}\right)$ : $(a, e, i, m)$ Distribuição espacial para o clima presente; (b, f, j, n) Impactos decorrentes do cenário RCP8.5 e desflorestamento para 2015 em relação ao clima presente; (c, g, k, o) Impactos decorrentes do cenário RCP8.5 e desflorestamento para 2050 em relação ao clima presente; (d, h, 1, p) Impactos decorrentes do cenário RCP8.5 e desflorestamento para 2100 em relação ao clima presente. As áreas onde as diferenças são significativas ao nível de confiança de $95 \%$ são marcadas por pontos pretos.

vou aumento na convergência de umidade em ambos cenários. Neste caso, predominou-se o Mecanismo de Retroalimentação Negativo (MRN) com a inclusão dos desflorestamentos, no qual, a redução relativa na evapotranspiração foi maior que a redução na precipitação conduzindo a um aumento na convergência de umidade sobre a bacia. A Fig. 6 apresenta um diagrama que mostra o Mecanismo de Retroalimentação. Apesar das mudanças no transporte e convergência de umidade, os efeitos da redução na evapotranspiração nos cenários de desfloresta- mento foram mais significativos para redução na precipitação no o fim do século XXI sobre a bacia do rio Madeira.

\subsection{Ramo terrestre do balanço de água}

\subsubsection{Desempenho da remoção do viés e calibração}

A Fig. 7 apresenta o ciclo anual médio da precipitação simulada pelo modelo Eta-BESM-OA (com e sem correção de viés) e as reanálises do Era-Interim (1979 a 2005) na bacia do rio Madeira. De forma geral, observa-se um melhor desempenho na representação da variação 


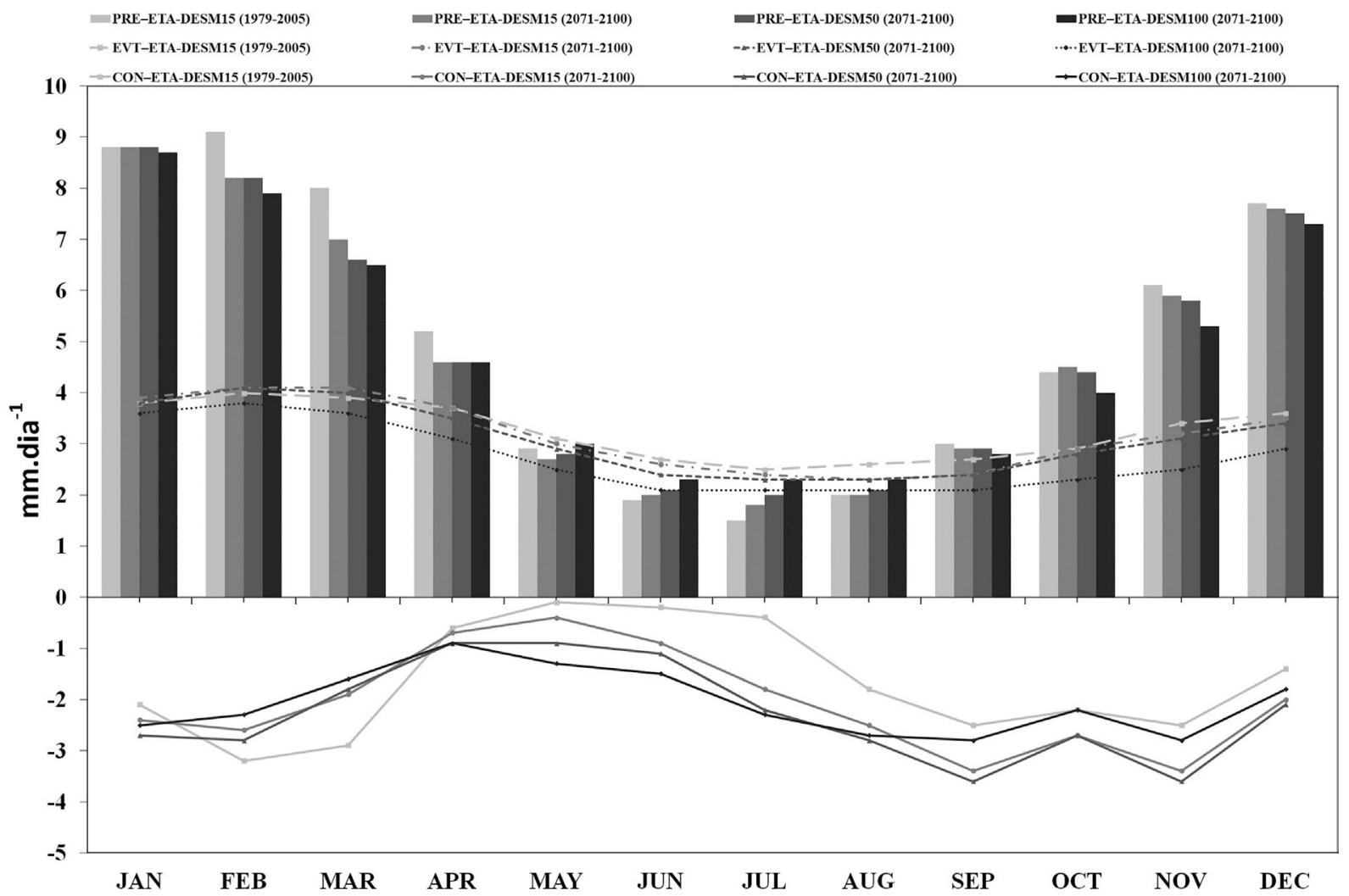

Figura 5 - Ciclo anual dos componentes do balanço de umidade: Precipitação (PRE, mm dia ${ }^{-1}$ ); Evapotranspiração da superfície (EVT, mm dia $\left.{ }^{-1}\right)$; Convergência de umidade (CON, mm dia ${ }^{-1}$ ) simulado pelo modelo Eta-BESM-OA para o clima presente (1979-2005) e período futuro (2071-2100) utilizando o cenário de emissão RCP 8.5 e cenários de desflorestamento para 2015, 2050 e 2100 para bacia do rio Madeira.

sazonal da precipitação com o modelo regional corrigido, principalmente na estação chuvosa onde os erros foram maiores. A precipitação média anual no modelo EtaBESM-OA corrigido (não corrigido) foi da ordem de $1.835 \mathrm{~mm} \mathrm{ano}^{-1}\left(1.368 \mathrm{~mm}\right.$ ano $\left.^{-1}\right)$, estando mais próximos daqueles observados nas reanálises Era-Interim $(1862 \mathrm{~mm}$ $\mathrm{ano}^{-1}$ ) e por Molinier et al., (1996) $\left(1.834 \mathrm{~mm} \mathrm{dia}{ }^{-1}\right)$. Entretanto, mesmo com a correção do viés o modelo regional subestimou a precipitação no período de dezembro a fevereiro (DJF) e superestimou na estação seca - junho a agosto - JJA. Para avaliar estatisticamente o desempenho do método de correção de viés utilizou-se o digrama de Taylor (Fig. 8). O desempenho é avaliado para os trimestres DJF, MAM, JJA e SON. Em todos os períodos, observou-se o ganho no desempenho da aplicação do método de correção do viés. A correlação ficou acima de 0.9 e o desvio padrão próximo dos valores observados (0.75 e 1.0) em todas as estações, indicando um satisfatório ajuste na precipitação sobre a bacia do rio Madeira. $\mathrm{Na}$ simulação com precipitação não corrigida a correlação variou de 0.6 a 0.8 com desvio padrão ficou em torno de 0.6. Na avaliação das descargas, as estações com melhor coeficiente de Nash-Sutcliffe (ENS) na correção do viés foram Guajará-Mirim (0.88), Porto Velho (0.90) e Manicoré $(0.86)$, conforme mostrado na Tabela 2.
Para a realização das simulações dos processos hidrológicos no clima presente e cenários futuros se fez necessário também a calibração do modelo MGB-IPH em todas as estações fluviométricas mostradas na Tabela 1. Utilizou-se para isso os dados de reanálises do ERAInterim (ECMWF) para o período 1990 a 1994. A Tabela 2 apresenta o desempenho do processo de calibração e da remoção do viés (erros sistemático do modelo regional) na simulação da vazão pelo modelo hidrológico MGB-IPH. As estações de Guajará-Mirim, Porto Velho, Ariquemes, Manicoré e Humboldt apresentaram bom desempenho no processo de calibração, pois o ENS esteve acima de 0.8 . Os menores erros no volume total $(\Delta V)$ foram nas estações de Guajará-Mirim, Manicoré e Humboldt. Com a correção do viés e a calibração do modelo MGB-IPH, as simulações de precipitação do modelo Eta-BESM-OA foram utilizadas para forçar o modelo MGB-IPH no clima presente e nas projeções futuras. Os dados de precipitação simulada pelo modelo regional para as projeções futuras (2071-2099) foram corrigidas supondo que o mesmo erro sistemático esteja no clima futuro.

\subsubsection{Descargas}

A Fig. 9 apresenta a variação sazonal da vazão e precipitação para o clima presente e cenários futuros de 


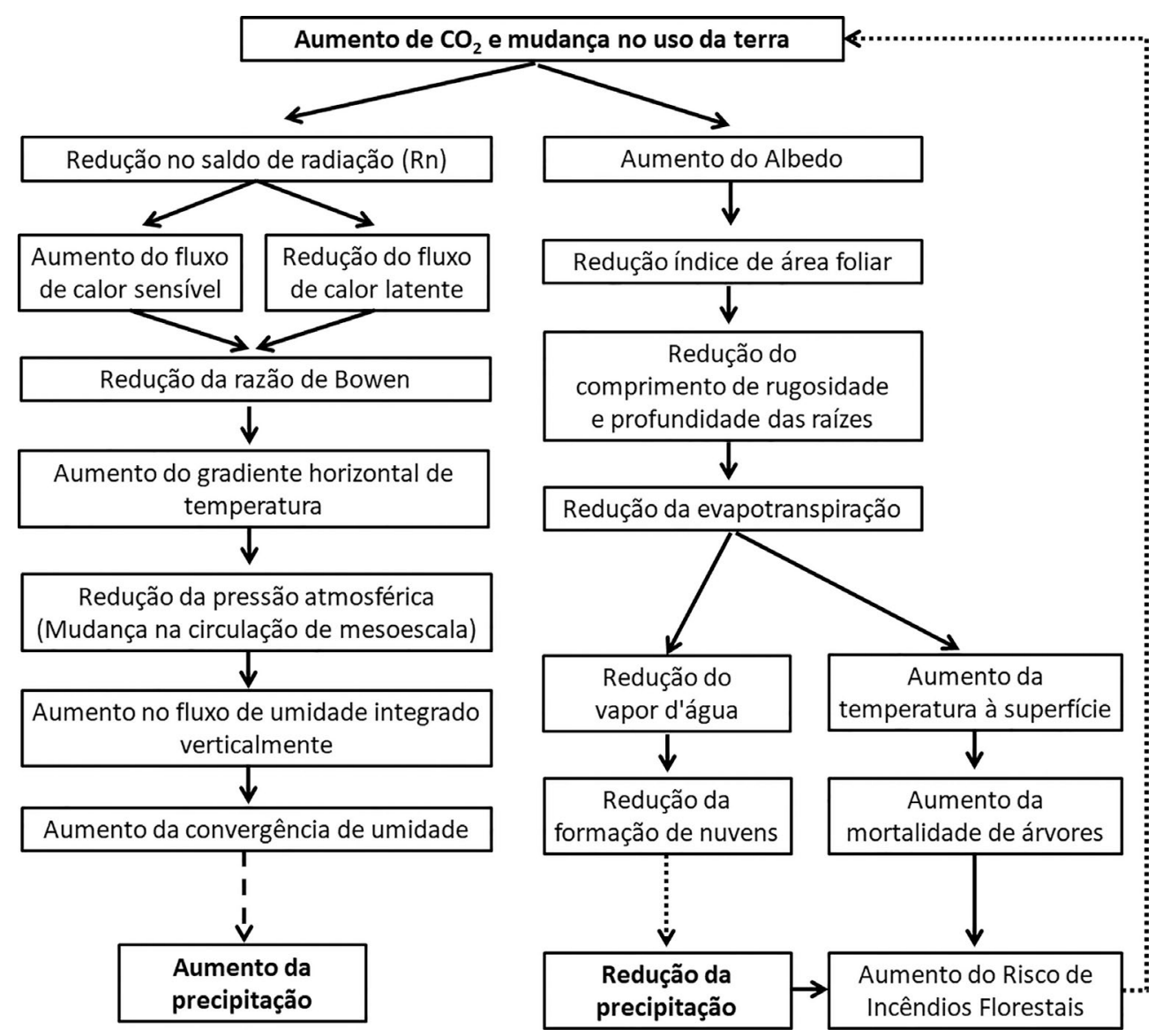

Figura 6 - Diagrama conceitual que resume os impactos do aumento de dióxido de carbono e mudanças no uso da terra. Setas sólidas: processos de interação biosfera-atmosfera; pontilhado: mecanismo de retroalimentação positivo; tracejado: mecanismo de retroalimentação negativo.

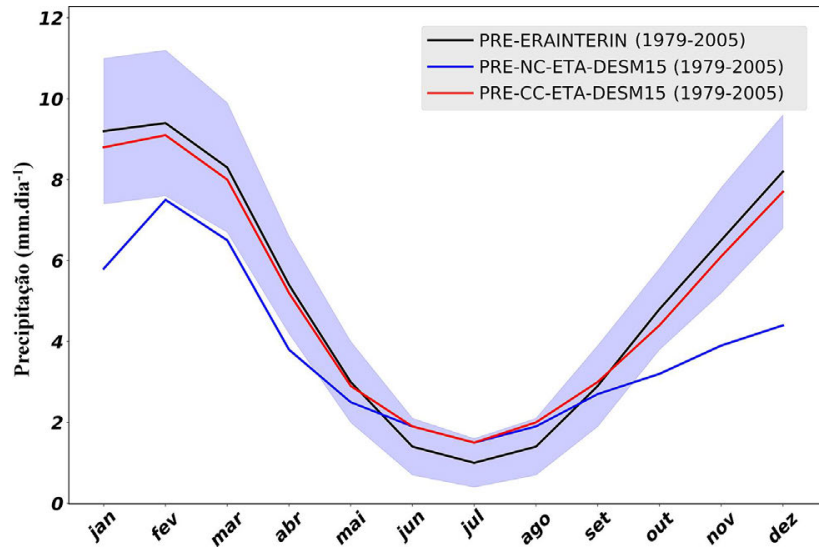

Figura 7 - Ciclo sazonal da precipitação $\left(\mathrm{mm} \cdot \mathrm{dia}^{-1}\right)$ simulada pelo modelo Eta sem correção (PRE-NC-ETA-DESM2015), Eta com correção (PRE-CC-ETA-DESM2015) e a reanálise do Era-Interim para a bacia do rio Madeira para o clima atual (1979-2005).

emissão de GEE's (RCP 8.5) com desflorestamento de 2015 e com projeções de desflorestamento para 2050 e 2100. Nas estações de Guajará-Mirim, Porto Velho, Humaitá e Manicoré se observou aumento intenso das

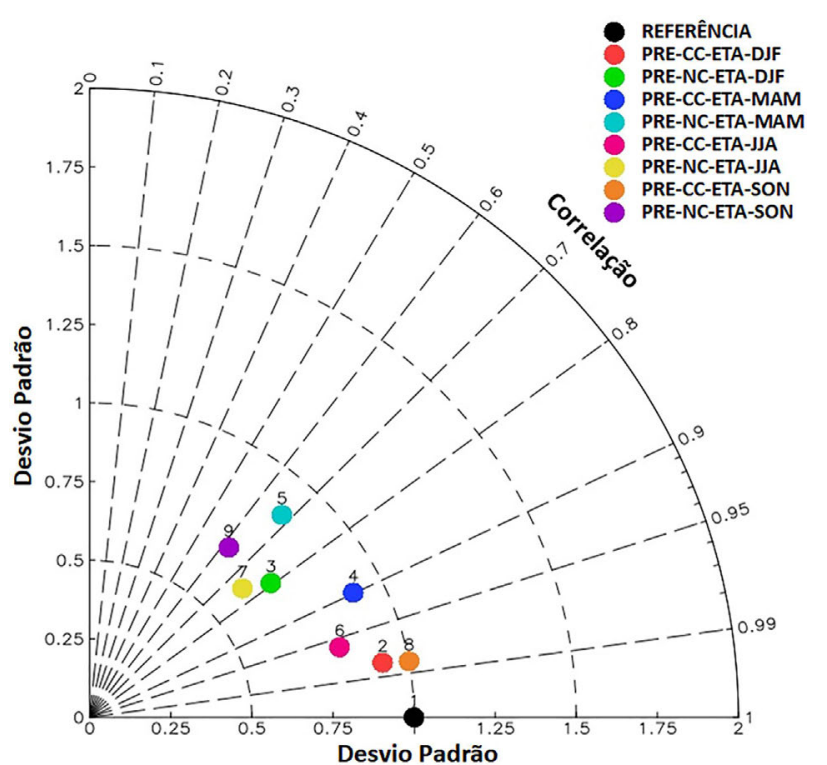

Figura 8 - Diagrama de Taylor para a precipitação média sazonal (DJF, MAM, JJA e SON) simulada pelo modelo Eta, sem correção (PRE-NCETA) e Eta com correção (PRE-CC-ETA), durante o período 1979-2005. $\mathrm{O}$ conjunto de dados de reanálises do Era-Interim é considerado como ponto de referência. 
vazões durante todo o ano para todos os cenários futuros. Entretanto, as mudanças na vazão foram maiores durante $o$ período de estiagem (Fig. 9 a, b, e, f). Os aumentos médios na descarga foram de $145 \%, 72 \%, 59 \%, 49 \%$ nas estações de Guajará-Mirim, Porto Velho, Humaitá e Manicoré, respectivamente. Nestas estações o efeito das mudanças no clima devido à emissão do GEE's foi mais importante do que aquele decorrente dos cenários de desflorestamento (2050 e 2100). Na estação seca o aumento observado nas descargas deve-se ao aumento na precipitação na maior parte da bacia do Madeira, principalmente nas regiões à montante (Figs. 3-4). Entretanto, na estação chuvosa o
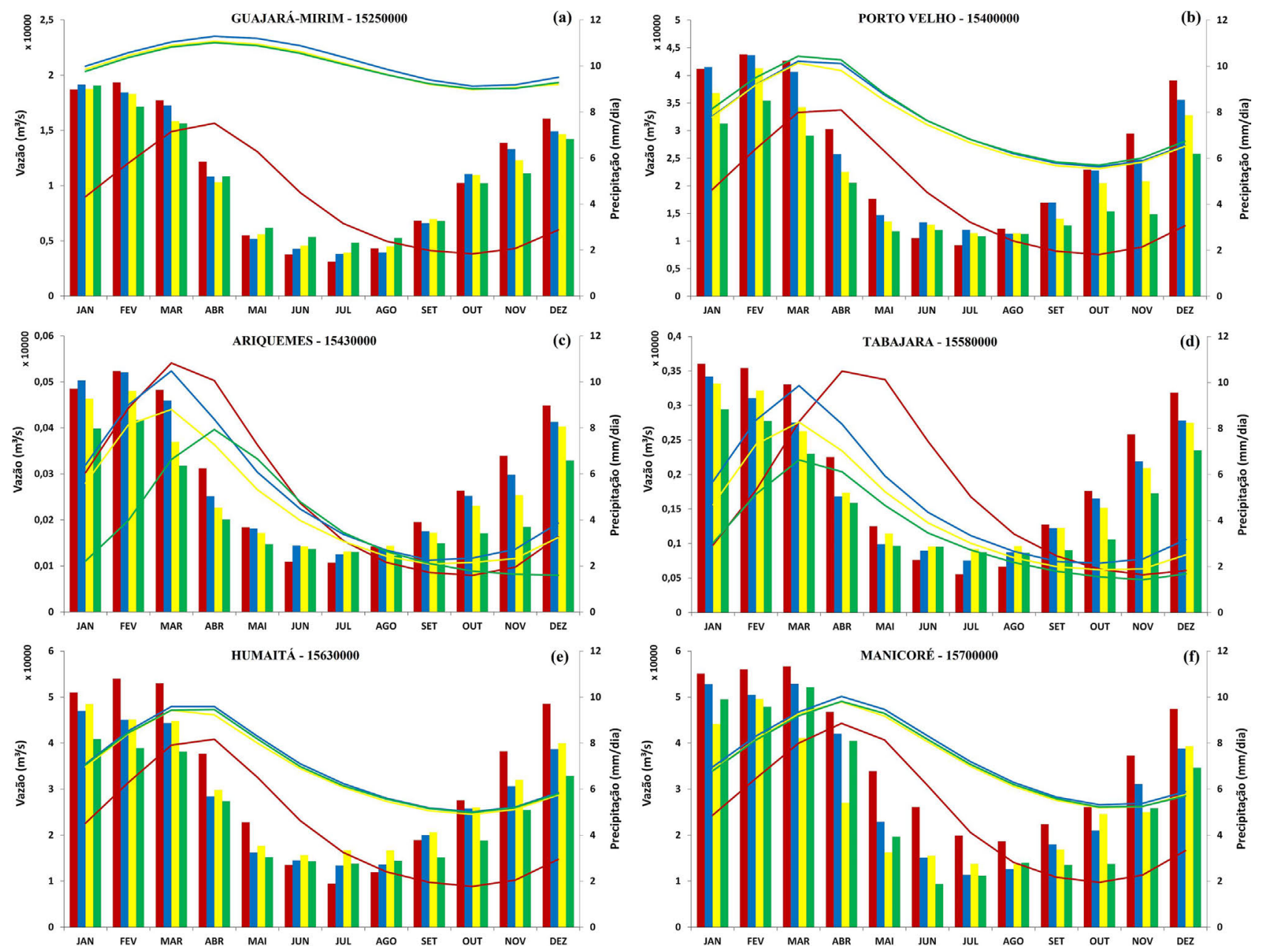

Figura 9 - Ciclo anual da vazão (linhas) e precipitação (barras) para o clima presente (vermelho) e cenários futuros de emissão de GEE's (RCP 8.5) e de desflorestamento para 2015 (azul), 2050 (amarelo) e 2100 (verde) sobre os postos fluviométricos localizados ao longo bacia do rio Madeira.

Tabela 2 - Desempenho do modelo MGB-IPH obtido para calibração (1990-1994) e validação (1995-2005): índice de eficiência de Nash-Sutcliffe entre vazões observadas e simuladas (ENS), índice de eficiência de Nash-Sutcliffe entre logaritmo das vazões observadas e simuladas (ENSlog) e o erro no volume total $(\Delta \mathrm{V})$.

\begin{tabular}{|c|c|c|c|c|c|c|c|c|}
\hline \multirow[b]{2}{*}{$\mathrm{N}^{\mathrm{o}}$} & \multirow[b]{2}{*}{ Código } & \multirow[b]{2}{*}{ Nome } & \multicolumn{3}{|c|}{ Calibração } & \multicolumn{3}{|c|}{ Validação } \\
\hline & & & ENS & ENSlog & $\Delta \mathrm{V}$ & ENS & ENSlog & $\Delta \mathrm{V}$ \\
\hline 1 & 15250000 & Guajará-Mirim & 0.89 & 0.81 & -7.27 & 0.88 & 0.76 & 6.01 \\
\hline 2 & 15400000 & Porto Velho & 0.88 & 0.87 & -11.06 & 0.90 & 0.83 & 3.19 \\
\hline 3 & 15430000 & Ariquemes & 0.82 & 0.65 & 11.28 & 0.72 & 0.49 & 27.41 \\
\hline 4 & 15580000 & Tabajara & 0.41 & 0.48 & 11.33 & 0.68 & 0.60 & 20.81 \\
\hline 5 & 15630000 & Humaitá & 0.70 & 0.60 & 20.70 & 0.60 & 0.83 & 11.86 \\
\hline 6 & 15700000 & Manicoré & 0.88 & 0.91 & -8.30 & 0.86 & 0.75 & 6.00 \\
\hline
\end{tabular}


aumento na vazão deve-se provavelmente a maior redução da evapotranspiração em relação à precipitação sobre parte da bacia, fazendo com que o escoamento (descarga) aumentasse nesses postos fluviométricos. De forma contrária, nas estações de Ariquemes e Tabajara as vazões foram reduzidas em todos os cenários, principalmente no período de enchente, onde as mudanças foram mais intensas. Na estação de Tabajara, além da redução nas descargas se observou uma antecipação de aproximadamente 2 meses no instante das vazões máximas. As estações de Tabajara e Ariquemes estão localizadas em afluentes do rio principal, enquanto as demais estão posicionadas no próprio rio Madeira. Desta forma, o rio principal controla o escoamento em seus afluentes. Assim, quando os níveis d'água nos grandes rios se elevam parte do volume d'água escoa para as respectivas planícies de inundação. Ao mesmo tempo, os pequenos afluentes são represados, diminuindo e muitas vezes invertendo o sentido do fluxo de vazões. Nestas estações se observou diferentes mudanças para cada cenário futuro de emissão e desflorestamento. $\mathrm{Na}$ estação de Ariquemes, as descargas foram reduzidas na estação úmida no cenário RCP 8.5 (8\%), e essa redução foi intensificada com os cenários de desflorestamento de 2050 (20\%) e 2100 (32\%). Comportamento semelhante foi observado na estação de Tabajara, onde as descargas foram reduzidas de $17 \%$ no cenário RCP 8.5 e de $29 \%$ e $40 \%$ nos cenários de desflorestamento de 2050 e 2100 , respectivamente.

\subsection{3. Áreas de inundação}

Além das vazões em rios de grandes bacias, a versão hidrodinâmica do MGB-IPH simula a extensão da área de inundação ao longo da bacia hidrográfica. A Fig. 10 apre- senta a variação sazonal da área inundação para o clima presente e cenários futuros de emissão de GEE's e de desflorestamentos sobre a bacia do rio Madeira. Durante todo o período observa-se aumento na área de inundação para todos os cenários futuros, e esse aumento foi maior durante a estação úmida. No cenário RCP 8.5 o aumento na área de inundação foi de $72 \%$, e com os cenários de desflorestamento os valores foram menos intensos variando de $65 \%$ para o cenário de 2050 e $68 \%$ no cenário de 2100 . O aumento da área inundada pode estar associado ao aumento na precipitação à montante da bacia do rio Madeira, próximo a Cordilheira dos Andes, e a mudança nos parâmetros do solo associada às alterações no uso da terra, pois o desflorestamento pode reduzir a evapotranspiração, modificar a descarga, e consequentemente aumentar as áreas inundadas sobre a bacia do rio Madeira.

\section{Conclusões}

No presente estudo, o Modelo Regional Eta e o Modelo Hidrológico de Grandes Bacias (MGB) foram utilizados para geração de simulações de mudanças climáticas a partir do cenário de emissão RCP 8.5 e de desflorestamentos futuros na bacia do Madeira. O objetivo desse estudo foi avaliar os efeitos do aumento dos GEE's projetados para o fim do século XXI e dos desflorestamentos futuros no ciclo da água (atmosférico e terrestre) na bacia do rio Madeira. No cenário RCP 8.5, modelo Eta-BESMOA apresentou sensibilidade sobre toda a bacia do Madeira, com aumento da ordem de $4.0{ }^{\circ} \mathrm{C}$ na temperatura. $\mathrm{O}$ aumento foi intensificado com os cenários de desflorestamentos de $2050\left(4.8^{\circ} \mathrm{C}\right)$ e $2100\left(6.2^{\circ} \mathrm{C}\right)$. Em todos os cenários futuros predominou a redução na precipitação na

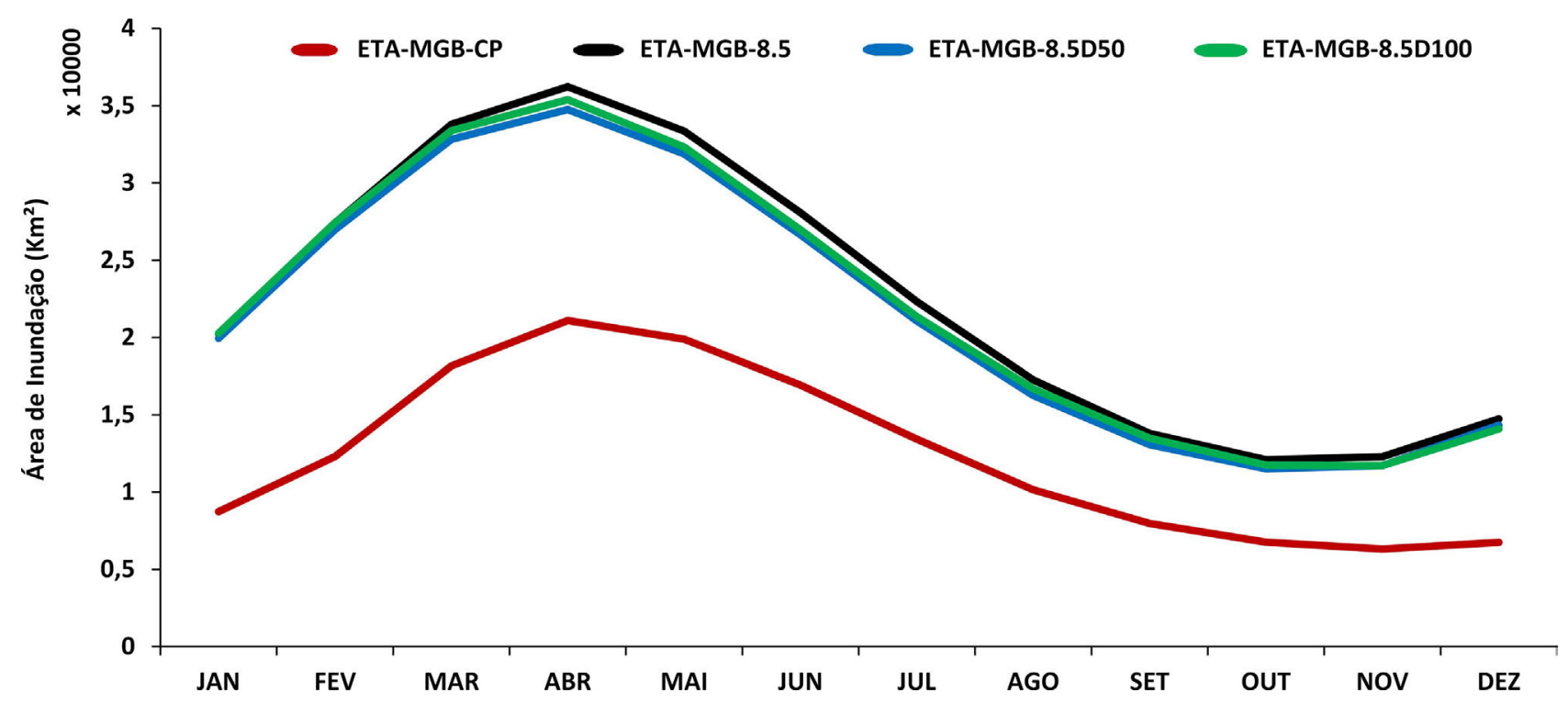

Figura 10 - Variação sazonal das áreas inundadas para o clima presente - CP (vermelho) e cenários futuros - CF de emissão de GEE's (RCP 8.5) e de desflorestamento para 2015 (preto), 2050 (azul) e 2100 (verde) para a bacia do rio Madeira. 
foz do rio Madeira, nas demais regiões da bacia observouse redução e aumento nas estações chuvosa e seca, respectivamente. Nos cenários de desflorestamento predominouse o Mecanismo de Retroalimentação Negativo, pois embora havendo reduções na precipitação e evapotranspiração, a convergência de umidade apresentou aumento em todos os cenários. Apesar do aumento na convergência de umidade, a redução na evapotranspiração nos cenários de desflorestamento teve papel preponderante na redução na precipitação sobre a bacia do rio Madeira. Com relação aos processos hidrológicos, observou-se aumento das descargas na maioria das estações para todos os cenários futuros RCP 8.5 e desflorestamento. O efeito das mudanças no clima devido à emissão do GEE's foi mais importante do que aquele decorrente dos cenários de desflorestamento. $\mathrm{O}$ aumento da precipitação na estação seca explicou em parte o aumento das vazões sobre a bacia do Madeira.

Os cenários futuros de emissão e de desflorestamento conduziram a um aumento na área de inundação. $O$ aumento na precipitação à montante da bacia e a mudança nos parâmetros do solo, associada às alterações no uso da terra, contribuíram para o aumento da área de inundação sobre a bacia do Madeira. As mudanças observadas na precipitação, evapotranspiração, descargas e inundações decorrentes dos fatores antropogênicos caracterizam-se em um cenário preocupante, pois podem desencadear alterações significativas no ciclo da água na bacia do rio Madeira. Essas alterações podem ter efeitos negativos com prejuízos e danos no meio ambiente, nos recursos hídricos, nos principais setores da economia (agricultura, indústria, mineração, navegação fluvial e da geração de energia), afetando de forma direta as comunidades que vivem às margens dos rios, principalmente as populações vulneráveis da bacia do Madeira.

\section{Agradecimentos}

Este artigo é parte da Dissertação de Mestrado do Programa de Pós-Graduação em Clima e Ambiente (CLIAMB) da Universidade do Estado do Amazonas (UEA) / Instituto Nacional de Pesquisas da Amazônia (INPA). Os autores agradecem a Agencia Nacional de Águas (ANA) e Brazilian Ministry of Science, Technology, and Innovation (MCTI) por financiamento adicional, o Centro de Previsão de Tempo e Estudos Climáticos - Instituto Nacional de Pesquisas Espaciais (CPTEC/INPE) por disponibilizar o Supercomputador TUPA para realização das integrações numéricas, o Laboratório de Modelagem do Sistema Climático Terrestre (LABCLIM) da UEA por disponibilizar a estrutura física computacional - Cluster Tambaqui. O primeiro autor agradece a Fundação de Amparo à Pesquisa do Estado do Amazonas - FAPEAM pela concessão da bolsa de estudo.

\section{Referências}

ALVES, L.M.; MARENGO, J.A.; FU, R.; BOMBARDI, R.J. Sensitivity of Amazon Regional Climate to Deforestation. American Journal of Climate Change, v. 6, n. 1, p. 7598, 2017.

CHOU, S.C.; LYRA, A.A.; MOURÃO, C.; DERECZYNSKI, C.; PILOTTO, I.; GOMES, J.; et al. Evaluation of the eta simulations nested in three global climate models. American Journal of Climate Change, v. 3, n. 5, p. 438, 2014a.

CHOU, S.C.; LYRA, A.; MOURÃO, C.; DERECZYNSKI, C.; PILOTTO, I.; GOMES, J.; BUSTAMANTE, J.; TAVARES, P.; SILVA, A.; RODRIGUES, D.; CAMPOS, D.; CHAGAS, D.; SUEIRO, G.; SIQUEIRA, G.; MARENGO, J. Assessment of Climate Change over South America under RCP 4.5 and 8.5 Downscaling Scenarios. American Journal of Climate Change, v. 3, n. 5, p. 512, 2014 b.

COLlischONN, W. Simulação HidrolóGica de Grandes Bacias. Tese de Doutorado em Engenharia de Recursos Hídricos e Saneamento Ambiental, Universidade Federal do Rio Grande do Sul, Porto Alegre. 270 pp, 2001.

COLLISCHONN, W.; ALLASIA D.G.; SILVA B.C.; TUCCI C.E.M. The MGB-IPH model for large-scale rainfall-runoff modeling. Hydrological Sciences Journal, v. 52, n. 5, p. 878-895, 2007.

DEE, D.P.; UPPALA, S.M.; SIMMONS, A.J.; BERRISFORD, P.; POLI, P.; KOBAYASHI, S.; ANDRAE, U.; BALMASEDA, M.A. et al. The ERA-Interim reanalysis: configuration and performance of the data assimilation system. Quarterly Journal of the Royal Meteorological Society, v. 137, n. 656, p. 553-597, 2011.

DOUGHTY, C.E.; METCALFE, D.B.; GIRARDIN, C.A.J.; AMÉZQUITA, F.F.; CABRERA, D.G.; HUASCO, W.H.; FELDPAUSCH, T.R. Drought impact on forest carbon dynamics and fluxes in Amazonia. Nature, v. 519, n. 7541, p. 78-82, 2015.

EK, M.B.; MITCHELL, K.E.; LIN, Y.; ROGERS, E.; GRUMMEN, P.; KOREN, V.; GAYNO, G.; TARPLEY, J.D. Implementation of Noah land surface model advances in the National Centers for Environmental Prediction operational mesoscale Eta model. Journal of Geophysical Research: Atmospheres, v. 108, D22, 2003.

ESPINOZA, J.C., MARENGO, J.A; RONCHAIL, J.; MOLINA, J.; NORIEGA, L.; GUYOT, J.L. The extreme 2014 flood in south-western Amazon basin: The role of tropical-subtropical South Atlantic SST gradient. Environmental Research Letters, v. 9, n. 12, p. 124007, 2014.

ESPINOZA VILLAR, J.C.; RONCHAIL, J.; GUYOT, J.L.; COCHONNEAU, G.; FILIZOLA, N.; LAVADO, W.; DE OLIVEIRA, E.; POMBOSA, R.; VAUCHEL, P. Spatiotemporal rainfall variability in the Amazon basin countries (Brazil, Peru, Bolivia, Colombia and Ecuador). International Journal of Climatology: A Journal of the Royal Meteorological Society, v. 29, n. 11, p. 1574-1594, 2009.

EVA, H. D.; HUBER, O.; ACHARD, F.; BALSLEV, H.; BECK, S.; BEHLING, H.; et al. A proposal for defining the geo- 
graphical boundaries of Amazonia; synthesis of the results from an expert consultation workshop organized by the European Commission in collaboration with the Amazon Cooperation Treaty Organization-JRC, Ispra, 7-8 June 2005. EC, 2005.

FELS, S.B.; SCHWARZKOPF, M.D. The simplified exchange approximation: a new method for radiative transfer calculations. Journal of the Atmospheric Sciences, v. 32, n. 7, p. 1475-1488, 1975.

FIGUEROA, S.N.; BONATTI, J.P.; KUBOTA, P.Y.; GRELL, G.A.; MORRISON, H.; BARROS, S.R.M.; et al. The Brazilian Global Atmospheric Model (BAM): Performance for tropical rainfall forecasting and sensitivity to convective scheme and horizontal resolution. Weather and Forecasting, v. 31, n. 5, p. 1547-1572, 2016.

FILIZOLA, N.; GUYOT, J.L.; MOLINIER, M.; GUIMARÃES, V.; OLIVEIRA, E.; FREITAS. M.A. Caracterização Hidrológica da Bacia Amazônica. In: Amazônia Uma Perspectiva Interdisciplinar, Rivas, A.; Freitas, C.E. (eds). Manaus: EDUA, p. 33-53, 2002.

GETIRANA, A.C.V.; BONNET, M.P.; ROTUNNO FILHO, O.C.; COLLISCHONN, W.; GUYOT, J.L.; SEYLER, F.; MANSUR, W.J. Hydrological modelling and water balance of the Negro River basin: evaluation based on in situ and spatial altimetry data. Hydrological Processes, v. 24, n. 22, p. 3219-3236, 2010.

GRELL G.A.; DEVENYI D. A generalized approach to parameterizing convection combining ensemble and data assimilation techniques. Geophys. Res. Lett., v. 29, n. 14, p. 38-1-38-4, 2002.

GRIFFIES S.M. Elements of MOM4p1. GFDL Ocean Group. Technical Report $N^{\circ}$ 6, NOAA. Geophysical Fluid Dynamics Laboratory, Princeton, USA, 444 pp., 2009.

HAY, L. E.; CLARK, M.P.; WILBY, R.L.; GUTOWSKI, W.J.; LEAVESLEY, G.H.; PAN, Z.; ARRITT, R.W.; TAKLE, E.S. Use of Regional Climate Model Output for Hydrologic Simulations. Journal of Hydrometeorology, v. 3, n. 5, p. 571-590, 2002.

INPE, 2017. Projeto PRODES: Monitoring the Brazilian Amazon Forest by Satellite: 2017. São José dos Campos, Brazil, disponível em http://www.obt.inpe.br/prodes/index. php, acesso em jan 2018.

IPCC (Intergovernmental Panel on Climate Change). Summary for Policymakers. In: Stocker, T.F.; Qin, D.; Plattner, G.K.; Tignor, M.; Allen, S.K.; Boschung, J.; Nauels, A.; Xia, Y.; Bex, V.; Midgley, P.M. (Eds). Climate Change 2013: The Physical Science Basis. Contribution of Working Group I to the Fifth Assessment Report of the Intergovernmental Panel on Climate Change. Cambridge: Cambridge University Press, v. 1535, 2013.

JANJIC, Z.I. The step-mountain Eta Coordinate Model: further developments of the convection, viscous sublayer and turbulence closure schemes. Monthly Weather Review, v. 122, n. 5, p. 927-945, 1994.

LACIS, A.A.; HANSEN, J.E. A parameterization of the absorption of solar radiation in earth's atmosphere. Journal of the Atmospheric Sciences, v. 31, n. 1, p. 118-133, 1974.

MARENGO, J.A.; NOBRE, C.A.; CHOU, S.C.; TOMASELLA, J.; SAMPAIO, G.; ALVES L.M.; OBREGÓN, G.O.;
SOARES, W.R.; BETTS, R.; KAY, G. Riscos das Mudanças Climáticas no Brasil: Análise Conjunta BrasilReino Unido Sobre os Impactos das Mudanças Climáticas e do Desmatamento na Amazônia. Projeto colaborativo realizado pelo Centro de Ciência do Sistema Terrestre (CCST), do Instituto Nacional de Pesquisas Espaciais (INPE), do Brasil e o Met Office Hadley Centre (MOHC), do Reino Unido. São José dos Campos: Instituto Nacional de Pesquisas Espaciais, 55 p., 2011.

MARENGO, J.A.; CHOU, S.C.; KAY, G.; ALVES, L.M.; PESQUERO, J.F.; SOARES, W.R.; SANTOS, D.C.; LYRA, A.A.; SUEIRO, G.; BETTS, R.; CHAGAS, D.J.; GOMES, J.L.; BUSTAMANTE, J.F.; TAVARES, P. Development of regional future climate change scenarios in South America using the Eta CPTEC/HadCM3 climate change projections: climatology and regional analyses for the Amazon, São Francisco and the Paraná River basins. Climate Dynamics, v. 38, n. 9-10, p. 1829-1848, 2012.

MARENGO, J.A.; ESPINOZA, J.C. Extreme seasonal droughts and floods in Amazonia: causes, trends and impacts. International Journal of Climatology, v. 36, n. 3, p. 10331050, 2016.

MELLOR, GEORGE L.; YAMADA, TETSUJI. Development of a turbulence closure model for geophysical fluid problems. Reviews of Geophysics, v. 20, n. 4, p. 851-875, 1982.

MESINGER, F. A blocking technique for representation of mountains in atmospheric models. Rivista di Meteorologia Aeronautica, v. 44, n. 1-4, p. 195-202, 1984.

MOLINIER, M.; GUYOT, J.L.; OLIVEIRA, E.; GUIMARAES, V. Les Regimes Hydrologiques De L'Amazone Et De Ses Affluents. In: L'Hydrologie Tropicale: Geoscience et Outil Pour le Developpement. Chevallier P. and Pouyaud B. (eds), Paris: AIHS, pp. 209-222, 1996.

NASH, J.E.; SUTCLIFFE, J.V. River flow forecasting through conceptual models. Part 1: A discussion of principles. Journal of Hydrology, v. 10, n. 3, p. 282-290, 1970.

NOBRE, P.; SIQUEIRA, L.S.P.; DE ALMEIDA, R.A.F.; MALAGUTTI, M.; GIAROLLA, E.; CASTELAO, G.P. BOTTINO, M.J.; KUBOTA, P.; FIGUEROA, S.N.; COSTA, M.C.; BAPTISTA JR.M.; IRBER JR.L.; MARCONDES, G.G. Climate simulation and change in the Brazilian climate model. Journal of Climate, v. 26, n. 17, p. 67166732, 2013.

PAIVA, R.C.D.; COLLISCHONN, W.; TUCCI, C.E.M. Large scale hydrologic and hydrodynamic modeling using limited data and a GIS based approach. Journal of Hydrology, v. 406, n. 3-4, p. 170-181, 2011.

PAIVA, R.C.D.; COLLISCHONN, W.; BUARQUE, D.C. Validation of a full hydrodynamic model for large scale hydrologic modelling in the Amazon. Hydrological Processes, v. 27, n. 3, p. 333-346, 2013.

PEREIRA, M.M.E. Integração de Modelos Hidrológicos e SIG na Analise de Processos de Outorga Quantitativa de Uso da Água: Aplicação na Bacia do Rio Dos Sinos - RS. Dissertação de Mestrado, Instituto de Pesquisas Hidráulicas, Universidade Federal do Rio Grande do Sul, Porto Alegre, Brasil, 89 p., 2010.

SAMPAIO, G.; NOBRE, C.; COSTA, M. H.; SATYAMURTY, P.; SOARES-FILHO, B. S., CARDOSO, M. Regional cli- 
mate change over eastern Amazonia caused by pasture and soybean cropland expansion. Geophysical Research Letters, v. 34, n. 17, 2007.

SESTINI, M.F.; ALVALÁ, R.C.S.; MELLO, E.M.K.; VALERIANO, D.M.; CHOU, S.C.; NOBRE, C.A.; PAIVA, J.A.C.; REIMER, E.S. Elaboração de Mapas de Vegetação para Utilização em Modelos Meteorológicos e Hidrológicos (INPE-8972-RPQ/730). São José dos Campos: Instituto Nacional de Pesquisas Espaciais, 74 p., 2002.

SILVA, B.C.; COLLISCHONN, W. Previsão de vazão com modelos hidroclimáticos. Revista Brasileira de Recursos Hídricos, v. 11, n. 3, p. 15-29, 2006.

SILVEIRA, L.G.T.D.; CORREIA, F.W.S.; CHOU, S.C.; LYRA, A.; GOMES, W.B.; VERGASTA, L.; SILVA, P.R.T. Reciclagem de precipitação e desflorestamento na Amazônia: um estudo de modelagem numérica. Revista Brasileira de Meteorologia, v. 32, n. 3, p. 417-432, 2017.

SIQUEIRA JÚNIOR, L, TOMASELLA, J.; RODRIGUEZ, D.A. Impacts of future climatic and land cover changes on the hydrological regime of the Madeira River basin. Climatic change, v. 129, n. 1-2, p. 117-129, 2015.

SOARES-FILHO, B.S.; ALENCAR, A.; NEPSTAD, D.; CERQUEIRA, G.; DIAZ, M.; RIVERO, S.; SOLÓRZANOS, L.; VOLL, E. Simulating the response of land-cover changes to road paving and governance along a major Amazon highway: the Santarém-Cuiabá corridor. Global Change Biology, v. 10, n. 5, p. 745-764, 2004.

SORRIBAS, M.V.; PAIVA, R.C.D.; MELACK, J.M.; BRAVO, J.M.; JONES, C.; CARVALHO, L. Projections of climate change effects on discharge and inundation in the Amazon basin. Climatic Change, v. 136, n. 3-4, p. 555-570, 2016.

SPIEGEL, M.R. Estatística. São Paulo: McGraw-Hill, 580 p., 1972.

TIEDTKE E.M. The sensitivity of the time-mean large-scale flow to cumulus convection in the ECMWF model. ECMWF Workshop on Convection in Large-Scale Models. Reading, England: European Centre for MediumRange Weather Forecasts, pp. 297-316, 1984.

TRANCOSO, R.; CARNEIRO FILHO, A.; TOMASELLA, J.; SCHIETTI, J.; FORSBERG, B.R.; MILLER, R.P. Deforestation and conservation in major watersheds of the Brazilian Amazon. Environmental Conservation, v. 36, n. 4, p. 277-288, 2009.

TUCCI, C.E.M.; MARENGO, J.A.; SILVA DIAS, P.L.; COLLISCHONN, W.; SILVA, B.C.; CLARKE, R.T.; CARDOSO, A.O.; JUAREZ, R.N.; SAMPAIO, G.; CHAN, C.S; TOMASELlA, J. Previsão de Vazões na Bacia do Rio São Francisco com Base na Previsão Climática. Relatório Técnico Final. Projeto OMM/98/00. Porto Alegre: ANEEL, 368 p, 2005.
VAN VUUREN D.P.; EDMONDS J.; KAINUMA M.L.T.; RIAHI K.; THOMSON A.; MATSUI T.; HURTT G.; LAMARQUE J.F.; MEINSHAUSEN M.; SMITH S.; GRAINER C.; ROSE S.; HIBBARD K.A.; NAKICENOVIC N.; KREY V., KRAM T. Representative concentration pathways: An overview. Climatic Change, v. 109, p. 95-116, 2011a.

VAN VUUREN D.P.; STEHFEST E.; DEN ELZEN M.G.J.; DEETMAN S.; HOF A.; ISAAC M.; KLEIN GOLDEWIJK K.; KRAM T.; MENDOZA BELTRAN A.; OSTENRIJK R.; VAN VLIET J.; VAN RUIJVEN B. RCP2.6: exploring the possibility to keep global mean temperature increase below 2 C. Climatic Change, v. 109, n. 1-2, p. 95, 2011 b.

WOOD, A.; MAURER, E.P.; KUMAR, A.; LETTENMAIER, D.P. Long-range experimental hydrologic forecasting for the eastern United States. Journal of Geophysical Research: Atmospheres, v. 107, n. D20, p. ACL6, 2002.

XUE Y.; ZENG F.J.; MITCHELL K.E.; JANJIC Z.; ROGERS E. The Impact of Land Surface Processes on Simulations of the U.S. Hydrological Cycle: A Case Study of the 1993 Flood Using the SsiB Land Surface Model in the NCEP Eta Regional Model. Monthly Weather Review, v. 129, n. 12, p. 2833-2860, 2001.

YAPO, P.O.; GUPTA, H.V.; SOROOSHIAN, S. Multi-objective global optimization for hydrologic models. Journal of Hydrology, v. 204, n. 1-4, p. 83-97, 1998.

ZHANG, K.; ALMEIDA CASTANHO, A.D.; GALBRAITH, D.R.; MOGHIM, S.; LEVINE, N.M.; BRAS, R.L.; COE, M.T.; COSTA, M.H.; MALHI, Y.; LONGO, M.; KNOX, R.G.; MCKNIGHT, S.; WANG, J.; MOORCROFT, P.R. The fate of Amazonian ecosystems over the coming century arising from changes in climate, atmospheric $\mathrm{CO} 2$, and land use. Global Change Biology, v. 21, n. 7, p. 25692587, 2015.

ZHAO, Q.; BLACK, T.L.; BALDWIN, M.E. Implementation of the cloud prediction scheme in the Eta Model at NCEP. Weather and Forecasting, v. 12, n. 3, p. 697-712, 1997.

\section{Endereços de Internet}

ANA - AGÊNCIA NACIONAL DAS ÁGUAS (Brasil). Hidroweb: Sistema de Informações Hidrológicas. Disponível em http://hidroweb.ana.gov.br.

INSTITUTO NACIONAL DE PESQUISAS ESPACIAIS INPE (2017). PRODES. Disponível em http://www.obt. inpe.br/prodes/index.php.

License information: This is an open-access article distributed under the terms of the Creative Commons Attribution License (type CC-BY), which permits unrestricted use, distribution and reproduction in any medium, provided the original article is properly cited. 